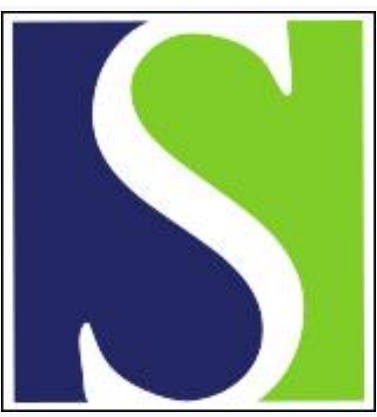

Scand J Work Environ Health 2012;38(6):553-559

https://doi.org/10.5271/sjweh.3322

Published online: 13 Sep 2012, Issue date: 01 Nov 2012

Nightshift work job exposure matrices and urinary 6-sulfatoxymelatonin levels among healthy Chinese women by Ji B-T, Gao Y-T, Shu X-O, Yang G, Yu K, Xue S-Z, Li H-L, Liao LM, Blair A, Rothman N, Zheng W, Chow W-H

Affiliation: Division of Cancer Epidemiology and Genetics, National Cancer Institute, Rockville, MD, USA. jib@mail.nih.gov

Refers to the following texts of the Journal: 2007;33(5):336-343 2008;34(1):5-22 2010;36(2):134-141

The following articles refer to this text: 2013;39(4):425-426; 2014;40(3):295-304

Key terms: aMT6s; cancer; China; job exposure matrix; melatonin; night shift; nighttime work; shift work; urinary 6-sulfatoxymelatonin; urine sample; woman

This article in PubMed: www.ncbi.nlm.nih.gov/pubmed/22975884 


\title{
Night shift work job exposure matrices and urinary 6-sulfatoxymelatonin levels among healthy Chinese women
}

\author{
by Bu-Tian Ji, DrPH, ${ }^{1}$ Yu-Tang Gao, MD, ${ }^{2}$ Xiao-Ou Shu, PhD, ${ }^{3}$ Gong Yang, MD, ${ }^{3}$ Kai Yu, PhD, ${ }^{1}$ Shou- \\ Zheng Xue, MD, ${ }^{1}$ Hong-Lan Li, MD, ${ }^{2}$ Linda M Liao, PhD, ${ }^{1}$ Aaron Blair, PhD, ${ }^{1}$ Nathaniel Rothman, PhD, ${ }^{1}$ \\ Wei Zheng, PhD, ${ }^{3}$ Wong-Ho Chow, PhD ${ }^{1}$
}

\begin{abstract}
Ji B-T, Gao Y-T, Shu X-O, Yang G, Yu K, Xue S-Z, Li H-L, Liao LM, Blair A, Rothman N, Zheng W, Chow W-H. Night shift work job exposure matrices and urinary 6-sulfatoxymelatonin levels among healthy Chinese women. Scand J Work Environ Health. 2012;38(6):553-559. doi:10.5271/sjweh.3322
\end{abstract}

Objective Six-sulfatoxymelatonin (aMT6s) is a primary urinary metabolite of melatonin. We examined the association between aMT6s levels and shift work estimated by a job exposure matrix (JEM) among healthy participants of the Shanghai Women's Health Study.

Methods Creatinine-adjusted aMT6s levels were measured in the urine samples of 300 women and related to JEM shift work categories.

Results Adjusted geometric means of aMT6s levels from urine samples collected before 08:00 hours were lower among persons holding nighttime shift work jobs. The adjusted aMT6s levels (ng/mg creatinine) were 8.36 [95\% confidence intervals $(95 \%$ CI) 4.47-15.6], 6.37 (95\% CI 3.53-11.5), 6.20 (95\% CI 3.33-11.5), 3.81 (95\% CI 2.02-7.19), and $3.70(95 \%$ CI 1.92-7.11) from the lowest (never held a shift work job) to the highest (current job likely involved all-night shift work) shift work JEM scores ( $\mathrm{P}=0.05)$.

Conclusion Our results indicate that night shift work JEM scores were significantly and inversely associated with aMT6s levels in early morning spot urine samples collected between 07:00-08:00 hours.

Key terms aMT6s; cancer; China; job exposure matrix; melatonin; nighttime work; shift work; urine sample.

Night shift work has been associated with both lower melatonin levels and an increased cancer risk in epidemiological studies (1-3). The International Agency for Research on Cancer (IARC) has classified shift work involving disruption of circadian rhythms as a probable cause of human cancer based on sufficient animal evidence but limited epidemiologic data (4). The investigation of the role of night shift work in relation to cancer risk in human populations is hampered by the inconsistent definition and measurement of shift work in epidemiologic studies. Only limited studies have collected data on shift work (5-11), while other studies have relied on methods such as the job exposure matrix (JEM) to estimate night shift work from lifetime occupational history or occupation data reported to census (12-15). Although JEM has been used extensively to evaluate a wide variety of occupational exposures in relation to disease risks, its use in studies of night shift work has been relatively limited. Reasons for the dearth of JEM-based shift work studies are unclear but may be partly due to the difficulties in using JEM to estimate night shift work and concern for the potentially sizable misclassification that may occur $(16,17)$. A decreased melatonin level during periods of night shift work is a hypothesized mechanism through which night shift work is linked to cancer risk (18). Melatonin is secreted by the pineal gland during the dark phase of the light-dark cycle in a 24-hour daily rhythm. In a typical nighttime sleep cycle, melatonin reaches its peak level during the early morning hours (around 02:00-03:00 hours), and the level remains low during day time $(19,20)$. Six-sulfatoxymelatonin (aMT6s) is a primary urinary metabolite of melatonin (21). Previous studies have found that night shift work or light exposure at night

1 Division of Cancer Epidemiology and Genetics, National Cancer Institute, Rockville, MD, USA.

2 Department of Epidemiology, Shanghai Cancer Institute, Shanghai, People's Republic of China.

3 Division of Epidemiology, Department of Medicine, Vanderbilt Epidemiology Center, Vanderbilt-Ingram Cancer Center, Vanderbilt University School of Medicine, Nashville, TN, USA. 
could reduce secretion of melatonin and was associated with lower levels of urinary aMT6s (21-29).

Epidemiologic studies of the association between urinary melatonin and shift work mainly measured aMT6s in 24-hour or morning first-void urine samples $(27,30)$. However, collection of 24-hour or morning first-void urine samples is challenging for most large prospective cohort studies. Daytime spot urine samples, however, have been collected in a few cohorts at the time of baseline interview, and these could be used in shift work investigations. An additional limitation is that not all cohort studies include a detailed shift work questionnaire. Many, however, have collected an occupational history (1-3). If future studies could rely on a shift work JEM and spot urine samples for assessment of melatonin levels, it would expand the opportunities for examining adverse health risk in relation to night shift work. The present pilot study was conducted to examine the association between night shift work JEM scores and aMT6s levels tested in spot urine samples among healthy Chinese women participating in the populationbased Shanghai Women's Health Study (SWHS) cohort.

\section{Methods}

The SWHS has been described in detail elsewhere (31). Between March 1997 and May 2000, all eligible women aged 40-70 years residing permanently in seven communities of urban Shanghai were invited to participate, 74942 (93\%) of whom responded. At baseline, in-person interviews were conducted to obtain information on demographic background, history of tobacco smoking and alcohol use, leisure-time physical activities, height and weight history, family history of cancer, reproductive factors, and a lifetime occupational history that included job title, factory name (industry), job descriptions, and years starting and ending the jobs. Over $88 \%$ of participants provided a spot urine sample at baseline. The samples were kept cold and processed within 6 hours of collection for long-term storage at $-70^{\circ} \mathrm{C}$. During the second followup four years later, a self-reported night shift work history was elicited. A written informed consent was obtained from all study participants. The Institutional Review Boards of all participating study centers in China and the United States approved the study.

An industrial hygienist familiar with local industrial conditions developed a night shift JEM based on data in the lifetime occupational history reported by all cohort participants at baseline. The JEM categorized all jobs into "never", "low", "median", and "high" likelihood of exposure to night shift work (32). By using the same definitions of the JEM night shift work categories on the current job at baseline when the urine samples were collected, we recategorized the exposure into 5 categories by adding 2 additional categories among those who were currently not involved in a night shift job: $1=$ never held a job involving night shift lifetime; $2=$ did not have a current night shift job at baseline (ie, at the time of urine collection) but had $>1$ job involving shift work in the past; $3=$ current job involving incidental night shift work (eg, reporters and army personnel); $4=$ current job likely involving the night shift, but entails working only part of the night or being on call (eg, physicians and bakers); and $5=$ current job involving all-night shifts without sleep (eg, nurses and certain production workers).

For the pilot study, only healthy women employed at the time of urine collection were included. Women were stratified and randomly selected within each stratum to provide equal numbers at each level of the JEM score and at four time segments of sample collection (early morning 07:00-8:00 hours, middle morning 08:01-10:00 hours, late morning 10:01-12:00, and afternoon 12:01 and later). A total of 300 women with urine samples were included.

Urinary aMT6s was assayed at the Johns Hopkins University Bayview Medical Center Core Laboratory using Bühlmann 6-sulfatoxymelatonin ELISA assay kit (ALPCO Cat\# 01-EK-M6S, Windham, NH, USA). For comparison, we also assayed urinary levels of cortisol, a major mediator of the neuroendocrine response to stress that may be influenced by circadian rhythm (26-28). Urinary-free cortisol concentration was measured by using APLCO cortisol urine ELISA assay kit (ALPCO Cat\# 33-10110, Windham, NH, USA). All urinary measurements were adjusted for creatinine [ng/mg creatinine $(\mathrm{Cr})]$ and transformed into logarithmic values for statistical analysis. After excluding subjects with outlier values (defined as $>3$ times the standard deviation from the logarithmic average), 296 subjects remained in all data analyses.

Data analyses were conducted using the SAS MIXED procedure by setting aMT6s as a response variable to fit linear regression models to calculate estimated means of aMT6s by night shift work JEM levels, sample collection time, and other covariates. These included: age at sample collection (age $40-<45$ and $45-70$ years), education levels (college or higher, high school, and middle schooland lower), body mass index (BMI, measured at baseline) (quartile: $\leq 21.1,>21.1-\leq 22.9,>22.9-\leq 25.4$, and $>25.4 \mathrm{~kg} / \mathrm{m}^{2}$ ), alcohol consumption (yes, no), menopausal status (pre- versus post-menopausal), number of live births ( $0-1$ and $>2$ children), and creatinine-adjusted urinary cortisol level (quartile: $\leq 136.5,>136.5-\leq 197.9$, $>197.9-\leq 297.1$, and $>297.1 \mathrm{ng} / \mathrm{mg} \mathrm{Cr}$ ). Additional adjustment in multivariate models for other factors potentially associated with aMT6s level (such as smoking, tea drinking, ever took Chinese medicine in the past 24 hours of urine collection, oral contraceptive 
use, and months of sample collection in a year) did not change the associations between urinary aMT6s or cortisol levels and night shift work JEM scores. Therefore, these factors were not included in the final models. All means were back-transformed to present results in the original scale of nanograms aMT6s or cortisol/mg Cr (geometric means).

\section{Results}

Of the 296 women in this study, the median age was 45 years, and $>47 \%$ had high school or greater education. The median BMI was $23.4 \mathrm{~kg} / \mathrm{m}^{2}$. Only $2.7 \%$ ever drank alcohol and $1.7 \%$ ever smoked cigarettes. Almost all women had at least a live birth (97.6\%), and $50(16.9 \%)$ had $>2$ live births. Less than one quarter $(23.3 \%)$ were post-menopausal at enrollment.

The arithmetic mean was $6.30 \mathrm{ng} / \mathrm{mg} \mathrm{Cr}$ with the range between the $25^{\text {th }}$ and $75^{\text {th }}$ percentiles $2.09-6.59$ $\mathrm{ng} / \mathrm{mg} \mathrm{Cr}$ for aMT6s and $104.6 \mathrm{ng} / \mathrm{mg} \mathrm{Cr}$ with the range between the $25^{\text {th }}$ and $75^{\text {th }}$ percentiles $118.4-229.5 \mathrm{ng} / \mathrm{mg}$ $\mathrm{Cr}$ for cortisol. Only geometric means were presented in the final analyses due to skewed distributions of the urine measurements. The overall geometric mean level of aMT6s was $4.07 \mathrm{ng} / \mathrm{mg} \mathrm{Cr}$ with the highest $(8.32 \mathrm{ng} /$ $\mathrm{mg} \mathrm{Cr}$ ) in urine samples collected in the early morning (07:00-08:00 hours), and consistently decreasing in samples collected later in the day (table 1). The levels were 4.54, 3.57, and $2.06 \mathrm{ng} / \mathrm{mg} \mathrm{Cr}$ in urine samples collected in middle morning (8:01-10:00 hours), late morning (10:01-12:00 hours), and afternoon (12:01 hours and later), respectively. A similar pattern was observed for urinary levels of cortisol, with the highest level (201.2 $\mathrm{ng} / \mathrm{mg} \mathrm{Cr}$ ) in samples collected in the early morning and the lowest level $(127.7 \mathrm{ng} / \mathrm{mg} \mathrm{Cr})$ in samples collected in the afternoon. The overall geometric mean level of cortisol was $167.1 \mathrm{ng} / \mathrm{mg} \mathrm{Cr}$.

Figure 1a shows the association between urinary

Table 1. Observed creatinine ( $\mathrm{Cr}$ )-adjusted geometric means (GM) of 6-sulfatoxymelatonin (aMT6s) and cortisol levels (ng/ $\mathrm{mg} \mathrm{Cr}$ ) by four time segments of urine sample collection (hour) in 296 urine samples, Shanghai Women's Health Study, China. [SD=standard deviation]

\begin{tabular}{|c|c|c|c|c|c|}
\hline \multirow[t]{2}{*}{ Sample collection time } & \multirow[t]{2}{*}{$\mathrm{N}$} & \multicolumn{2}{|c|}{$\begin{array}{c}\text { aMT6s } \\
\text { (ng/mg Cr) }\end{array}$} & \multicolumn{2}{|c|}{$\begin{array}{c}\text { Cortisol } \\
\text { (ng/mg Cr) }\end{array}$} \\
\hline & & GM & SD & GM & SD \\
\hline 07:00-08:00 & 73 & 8.32 & 2.32 & 201.2 & 1.76 \\
\hline 08:01-10:00 & 75 & 4.54 & 2.12 & 191.7 & 1.55 \\
\hline $10: 01-12: 00$ & 74 & 3.57 & 2.10 & 158.2 & 1.46 \\
\hline $12: 01-19: 00$ & 74 & 2.06 & 1.62 & 127.7 & 1.56 \\
\hline Any time & 296 & 4.07 & 2.38 & 167.1 & 1.64 \\
\hline
\end{tabular}

aMT6s levels and night shift JEM scores by the four different time segments of urine sample collection. The inverse trends of aMT6s by night shift work JEM scores was only seen in the early morning urine samples. No associations between urinary aMT6s and night shift work JEM scores were observed in urine samples collected at later times of the day or in all urine samples. In contrast, urinary cortisol levels were not associated with JEM scores in samples collected at any time during the day, including the early morning urine samples (figure 1b).

We conducted further analysis restricted to samples collected during 07:00-8:00 hours. In multivariate models, we examined whether aMT6s levels varied by lifestyle and reproductive factors (table 2). Urinary aMT6s levels tended to be higher among women who were $<45$ years, had at least some college education, did not consume alcohol, had only $\leq 1$ live birth, or were postmenopausal at the time of urine donation, although the differences were not statistically significant. The aMT6s level was lowest among women in the highest quartile of BMI $\left(>25.4 \mathrm{~kg} / \mathrm{m}^{2}\right)$ or with below median level of urinary cortisol.

Urinary aMT6s levels from early-morning urine collection decreased with increasing JEM scores (table 3). The estimated aMT6s levels were reduced in all night shift JEM categories in the fully adjusted models that included age, education, BMI, alcohol consumption, menopausal status, number of live births, and urinary cortisol levels. The adjusted aMT6s levels decreased from $8.36 \mathrm{ng} / \mathrm{mg} \mathrm{Cr}$ [95\% confidence interval $(95 \% \mathrm{CI})$ 4.47-15.6] in the lowest night shift JEM score category (never held a job with shift work in lifetime) to $3.70 \mathrm{ng} /$ $\mathrm{mg} \mathrm{Cr}(95 \%$ CI 1.92-7.11) in the highest category (current job likely involved all-night shift work) $(\mathrm{P}=0.05)$.

\section{Discussion}

In this cross-section of middle-aged working Chinese women, we found that aMT6s levels in spot urine samples collected in the early morning (07:00-8:00 hours) consistently decreased with increasing likelihood of night shift work as indicated by the JEM score. In contrast, inverse associations between night shift work and aMT6s levels were not observed in urine samples collected after 08:00 hours.

Exposure to light at night has been documented to suppress the secretion of melatonin (19, 21-27). Night shift work, a surrogate for exposure to light at night, has also been shown to lower urinary aMT6s levels among exposed workers (22-29). Our observation of an inverse association between night shift work and aMT6s levels in the early morning urine samples is consistent with 

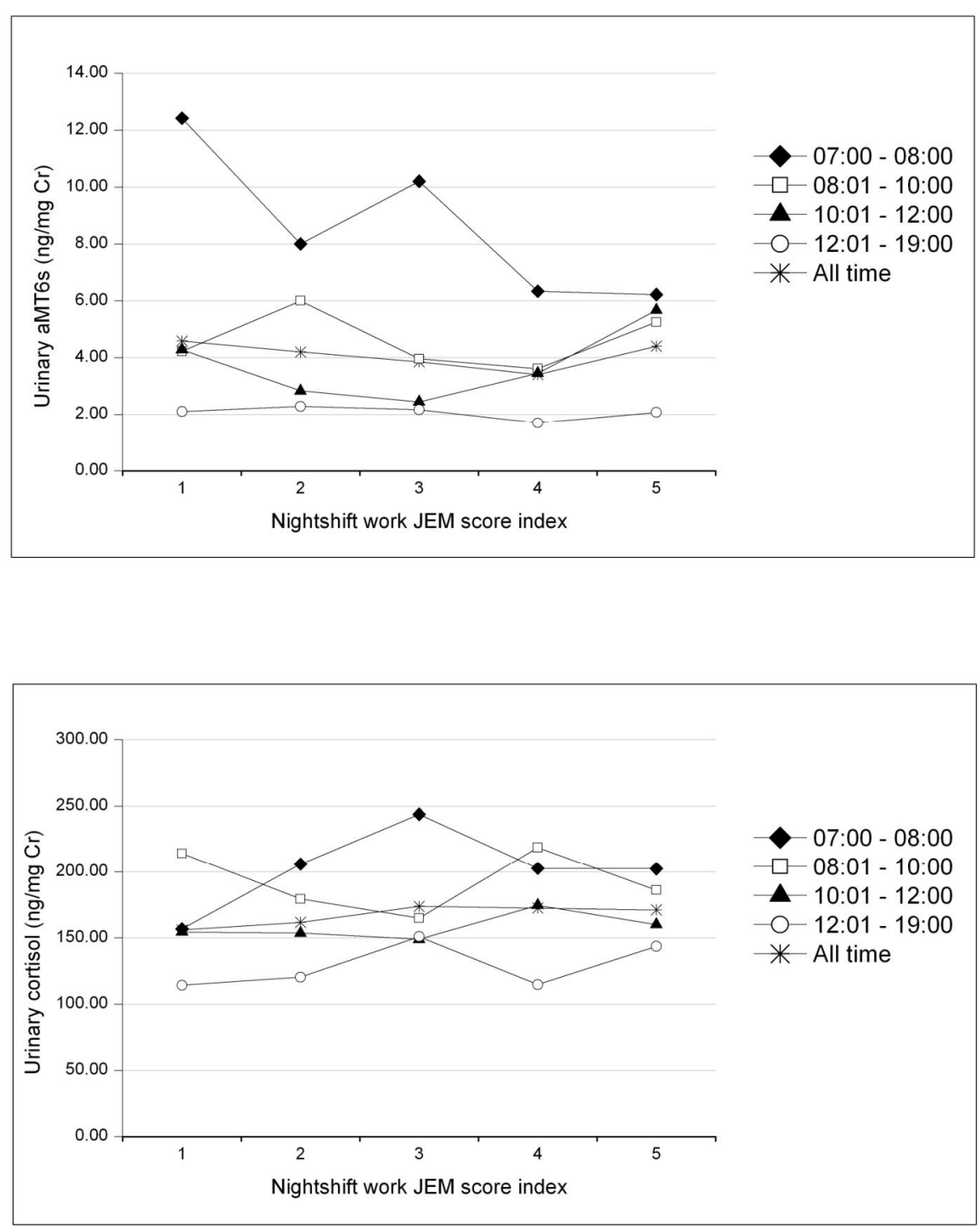

Figure 1a. Observed creatinineadjusted geometric mean 6-sulfatoxymelatonin (aMT6s) levels (ng/mg $\mathrm{Cr}$ ) by nightshift job exposure matrix (JEM) score index, Shanghai Women's Health Study, China. Night shift JEM score index: $1=$ neverhad a night shift workjob in lifetime; $2=$ currently did not have a nightshift work job buthad $\geq 1$ in the past; $3=$ current job had a nightshift JEM score of $1 ; 4=$ current job had a nightshift JEM score of 2; $5=$ current job had a night shift JEM score of 3 . Different sample collection times (07:00-8:00, 8:01-10:00, 10:01-12:00, 12:01-19:00 hours, and all time periods).

Figure 1b. Observed creatinineadjusted geometric mean cortisol levels $(\mathrm{ng} / \mathrm{mg} \mathrm{Cr}$ ) by nightshift job exposure matrix (JEM) score index, Shanghai Women's Health Study, China. Night shift JEM score index: $1=$ never had a nightshift work job in lifetime; 2=currently did not have a night shift work job but had $\geq 1$ in the past; $3=$ current job had a nights hift JEM score of 1; 4=current job had a nightshift JEM score of 2; $5=$ current job had a night shift JEM score of 3. Different sample collection times (07:00-8:00, 8:01-10:00, 10:01-12:00, 12:01-19:00 hours, and all time periods). previous work and suggests that spot urine samples collected in the early morning may be used for studies using aMT6s and shift work. Since melatonin level quickly declines throughout the course of a day (19-20), spot urine samples collected later in the day would not be suitable for evaluation of aMT6s levels as suggested by its lack of correlation with night shift work in samples collected after 08:00 hours in our study.

The reliability of occupational exposure assessments based on JEM has been questioned since this approach depends largely on the subjective professional judgment of an industrial hygienist or occupational expert (33). Construction of a JEM for shift work maybe especially challenging. Our findings of an inverse association between night shift work JEM and aMT6s levels in early-morning urine samples, however, provides some validation of the JEM approach for the assessment of shift work in our study population. Although the shift work JEM developed for the SWHS must have considerable misclassification error, based on the correlation with urinary aMT6s, it would appear to be useful for epidemiologic evaluations. The specificity of the associations of night shift work with aMT6s, but not with urinary cortisol levels, also adds credibility to our finding. This lack of an association between urinary cortisol levels and night shift JEM score in the SWHS pilot resembles findings among policemen where long-term night shift work was also not associated with the cortisol response (34). Some previous studies, however, have found that night shift work inversely reduced cortisol secretion (35-36). Since many epidemiologic studies did not collect information on shift work, but most collected 
Table 2. Estimated [creatinine (Cr)-adjusted] geometric means (GM) of urinary 6-sulfatoxymelatonin (aMT6s) by lifestyle factors in the early-morning urine samples, Shanghai Women's Health Study, China. [ $95 \% \mathrm{Cl}=95 \%$ confidence interval; $\mathrm{BMl}=$ body mass index]

\begin{tabular}{|c|c|c|c|c|}
\hline Lifestyle factors & $\mathrm{N}$ & $\begin{array}{c}\mathrm{GM} \\
\text { (ng/mg Cr) }\end{array}$ & $95 \% \mathrm{Cl}$ & P-value \\
\hline $\begin{array}{l}\text { Age at sample collection } \\
40-<45 \text { years } \\
45-70 \text { years }\end{array}$ & $\begin{array}{l}41 \\
32\end{array}$ & $\begin{array}{l}6.32 \\
5.55\end{array}$ & $\begin{array}{r}3.47-11.51 \\
3.35-9.20\end{array}$ & 0.57 \\
\hline $\begin{array}{l}\text { Education } \\
\text { College or higher } \\
\text { High school } \\
\text { Middle school and lower }\end{array}$ & $\begin{array}{l}17 \\
24 \\
32\end{array}$ & $\begin{array}{l}7.49 \\
4.78 \\
5.80\end{array}$ & $\begin{array}{r}4.16-13.50 \\
2.54-9.00 \\
3.31-10.16\end{array}$ & 0.33 \\
\hline $\begin{array}{l}\text { BMI }\left(\mathrm{kg} / \mathrm{m}^{2}\right)^{\text {a }} \\
\text { Q1 }(\leq 21.1) \\
\text { Q2 }(>21.1-\leq 22.9) \\
\text { Q3 }(>22.9-\leq 25.4) \\
\text { Q4 }(>25.4)\end{array}$ & $\begin{array}{l}19 \\
18 \\
17 \\
19\end{array}$ & $\begin{array}{l}6.45 \\
6.13 \\
8.35 \\
3.73\end{array}$ & $\begin{array}{r}3.42-12.17 \\
3.14-11.96 \\
4.74-14.71 \\
2.06-6.73\end{array}$ & 0.06 \\
\hline $\begin{array}{l}\text { Ever alcohol consumption } \\
\text { Yes } \\
\text { No }\end{array}$ & $\begin{array}{r}2 \\
71\end{array}$ & $\begin{array}{l}4.29 \\
8.18\end{array}$ & $\begin{array}{l}1.59-11.59 \\
5.57-12.02\end{array}$ & 0.25 \\
\hline $\begin{array}{l}\text { Number of live births } \\
0-1 \\
>2\end{array}$ & $\begin{array}{l}62 \\
11\end{array}$ & $\begin{array}{l}6.95 \\
5.05\end{array}$ & $\begin{array}{r}3.75-12.89 \\
2.62-9.73\end{array}$ & 0.41 \\
\hline $\begin{array}{l}\text { Menopausal status } \\
\text { Post-menopause } \\
\text { Pre-menopause }\end{array}$ & $\begin{array}{l}10 \\
63\end{array}$ & $\begin{array}{l}5.59 \\
6.28\end{array}$ & $\begin{array}{r}3.27-9.56 \\
3.26-12.10\end{array}$ & 0.72 \\
\hline $\begin{array}{l}\text { Cortisol a } \\
\text { Q1 }(\leq 136.5) \\
\text { Q2 }(>136.5-\leq 197.9) \\
\text { Q3 }(>197.9-\leq 297.1) \\
\text { Q4 }(>297.1)\end{array}$ & $\begin{array}{l}18 \\
19 \\
18 \\
18\end{array}$ & $\begin{array}{l}9.16 \\
6.21 \\
4.12 \\
5.26\end{array}$ & $\begin{array}{r}5.04-16.64 \\
3.46-11.13 \\
2.19-7.77 \\
2.79-9.89\end{array}$ & 0.05 \\
\hline
\end{tabular}

a Quartiles of BMI and cortisol levels were cut according to their distributions in the early-morning urine samples.

lifetime occupational history, the ability to use night shift JEM for exposure characterization considerably broadens opportunities for further evaluation of health effects of shift work. However, it is unclear whether this approach, ie, using JEM to assess shift work exposure and using spot urine collected in the early morning to assess melatonin levels, would work as effectively in studies conducted in other settings. Individuals in Shanghai do not have as many lifetime jobs as may be the case in other populations. Our results are encouraging, but additional pilot work may be necessary for studies conducted under different settings.

Our study was limited in that we were not able to verify the night shift work JEM score directly because information on night shift work pattern was not collected for each job in the participants' occupational history. However, the JEM scoring was conducted by an experienced, local industrial hygienist who is familiar with the Shanghai work environment. Our study was also limited by the lack of sequential urine samples collected during different times of the day including first-void urine samples for the same individuals to examine whether the relative associations with JEM scores can be maintained
Table 3. Estimated geometric means (GM) of urinary 6-sulfatoxymelatonin (aMT6s) by nightshift job exposure matrix (JEM) score index in the early-morning urine samples, Shanghai Women's Health Study, China. [ $95 \% \mathrm{Cl}=95 \%$ confidence interval; $\mathrm{BMI}=$ body mass index; $\mathrm{Cr}=$ creatine]

\begin{tabular}{|c|c|c|c|c|c|}
\hline \multirow{2}{*}{$\begin{array}{l}\text { Night shift } \\
\text { JEM score } \\
\text { index }{ }^{a}\end{array}$} & \multirow[t]{2}{*}{$N$} & \multicolumn{2}{|c|}{ Non-adjusted } & \multicolumn{2}{|c|}{ Adjusted b } \\
\hline & & $\begin{array}{c}\mathrm{GM} \\
\text { (ng/mg Cr) }\end{array}$ & $95 \% \mathrm{Cl}^{\mathrm{c}}$ & $\begin{array}{c}\mathrm{GM} \\
\text { (ng/mg Cr) }\end{array}$ & $95 \% \mathrm{Cl}^{\mathrm{d}}$ \\
\hline 1 & 14 & 12.42 & $8.03-19.22$ & 8.36 & $4.47-15.63$ \\
\hline 2 & 15 & 8.01 & $5.25-12.20$ & 6.37 & $3.53-11.46$ \\
\hline 3 & 15 & 10.21 & $6.70-15.56$ & 6.20 & $3.33-11.52$ \\
\hline 4 & 15 & 6.34 & $4.16-9.67$ & 3.81 & $2.02-7.19$ \\
\hline 5 & 14 & 6.23 & $4.03-9.63$ & 3.70 & $1.92-7.11$ \\
\hline
\end{tabular}

a Nightshift JEM score index: 1=never had a night shift work job in lifetime; $2=$ currently did not have a night shift work job but had $\geq 1$ in the past; $3=$ current job had a night shift JEM score of $1 ; 4=$ current job had a nightshift JEM score of 2; $5=$ current job had a night shift JEM score of 3 .

b GM of Cr-adjusted aMT6s urinary concentration controlled for age (40-<45 and 45-70 years); education (college or higher, high school, and middle school and lower), BMI ( $\leq 21.1,>21.1-\leq 22.9,>22.9-$ $\leq 25.4$, and $>25.4 \mathrm{~kg} / \mathrm{m}^{2}$ ), ever alcohol consumption (ever, never), menopausal status (pre- and post-menopausal), number of live births $(0-1$ and $\geq 2$ children), and urinary cortisol level $(\leq 136.5,>136.5-$ $\leq 197.9,>197.9-\leq 297.1$, and $>297.1 \mathrm{ng} / \mathrm{mg} \mathrm{Cr}$ ).

c P-value for trend $=0.11$.

d $\mathrm{P}$-value for trend $=0.05$.

using samples stratified by time segment of collection, despite the generally lower levels of aMT6s in samples collected later in the day than in samples collected before 08:00 hours. In addition, urine aMT6s levels in our study were relatively lower compared to the levels in other urine assays from different populations (30, 37-39). The possible reason might be due largely to not using the first-void spot urine samples since the urine melatonin levels are very time-sensitive and quickly reduced during daytime.

In conclusion, JEM scores of night shift work as a surrogate for light exposure at night were significantly and inversely associated with urinary aMT6s levels in spot urine samples collected in the early morning (07:00-8:00 hours).

\section{Acknowledgment}

This study was supported by the US National Institutes of Health (NIH) (grant R37 CA070867) and the Intramural Research Program of the NIH, Division of Cancer Epidemiology and Genetics (contract NO2CP-11010-66). This publication was also made possible by Grant Number UL1 RR 025005 from the National Center for Research Resources (NCRR), a component of the NIH, and NIH Roadmap for Medical Research. Its contents are solely the responsibility of the authors 
and do not necessarily represent the official view of NCRR or NIH. Information on NCRR is available at http://www.ncrr.nih.gov/. Information on re-engineering the clinical research enterprise can be obtained from http://nihroadmap.nih.gov/clinical research/overviewtranslational.asp. The authors also thank Ying Ni at the Johns Hopkins University Bayview Medical Center Core Laboratory for laboratory analyses and David Check at the National Cancer Institute for development of figures.

The authors declare no conflict of interest.

\section{References}

1. Kolstad HA. Night shift work and risk of breast cancer and other cancers - a critical review of the epidemiologic evidence. Scand J Work Environ Health. 2008;34(1):5-22. http://dx.doi. org/10.5271/sjweh.1194.

2. Wang XS, Armstrong MEG, Cairns BJ, Key TJ, Travis RC. Shift work and chronic disease: the epidemiological evidence. Occup Med. 2011;61:76-89. http://dx.doi.org/10.1093/ occmed/kqr001.

3. Stevens RG, Hansen J, Costa G, Haus E, Kauppinen, T, Aronson KJ, et al. Considerations of circadian impact for defining 'shift work' in cancer studies: IARC Working Group Report. Occup Environ Med. 2011;68:154-62. http://dx.doi. org/10.1136/oem.2009.053512.

4. Straif K, Baan R, Grosse Y, Secretan B, El Ghissassi F, Bouvard V, et al. Carcinogenicity of shift work, painting, and fire-fighting. Lancet Oncol. 2007;8:1065-6. http://dx.doi. org/10.1016/S1470-2045(07)70373-X.

5. Schernhammer ES, Laden F, Speizer FE, Willett WC, Hunter DJ, Kawachi I, et al. Rotating night shifts and risk of breast cancer in women participating in the nurses' health study. J Natl Cancer Inst. 2001;93:1563-8. http://dx.doi.org/10.1093/ jnci/93.20.1563.

6. Davis S, Mirick D, Stevens RG. Night shift work, light at night, and risk of breast cancer. J Natl Cancer Inst. 2001;93:1557-62. http://dx.doi.org/10.1093/jnci/93.20.1557.

7. Schernhammer ES, Kroenke CH, Laden F, Hankinson SE. Night work and risk of breast cancer. Epidemiology. 2006;17:10811. http://dx.doi.org/10.1097/01.ede.0000190539.03500.c1.

8. O'Leary ES, Schoenfeld ER, Stevens RG, Kabat GC, Henderson K, Grimson R, et al. Electromagnetic Fields and Breast Cancer on Long Island Study Group. Shift work, light at night, and breast cancer on Long Island, New York. Am J Epidemiol. 2006;164:358-66. http://dx.doi.org/10.1093/aje/ kwj211.

9. Lie JA, Roessink J, Kjaerheim K. Breast cancer and night work among Norwegian nurses. Cancer Causes Control. 2006;17:3944. http://dx.doi.org/10.1007/s10552-005-3639-2.

10. Pesch B, Harth V, Rabstein S, Baisch C, Schiffermann M, Pallapies D, et al. Night work and breast cancer-results from the German GENICA study. Scand J Work Environ Health. 2010;36:134-41. http://dx.doi.org/10.5271/sjweh.2890.
11. Kubo T, Ozasa K, Mikami K, Wakai K, Fujino Y, Watanabe $\mathrm{Y}$, et al. Prospective cohort study of the risk of prostate cancer among rotating-shift workers: findings from the Japan collaborative cohort study. Am J Epidemiol. 2006;164:549-55. http://dx.doi.org/10.1093/aje/kwj232.

12. Hansen J. Increased breast cancer risk among women who work predominantly at night. Epidemiology. 2001;12:74-7. http://dx.doi.org/10.1097/00001648-200101000-00013.

13. Schwartzbaum J, Ahlbom A, Feychting M. Cohort study of cancer risk among male and female workers. Scand J Work Environ Health. 2007;35(5):336-43. http://dx.doi. org/10.5271/sjweh.1150.

14. Lahti TA, Partonen T, Kyyrönen P, Kauppinen T, Pukkala E. Night-time work predisposes to non-Hodgkin lymphoma. Int J Cancer. 2008;123:2148-51. http://dx.doi.org/10.1002/ ijc. 23566 .

15. Kauppinen T, Heikkilä P, Plato N, Woldbaek T, Lenvik K, Hansen J, et al. Construction of job-exposure matrices for the Nordic Occupational Cancer Study (NOCCA). Acta Oncol 2009;18:1-11.

16. Siemiatycki J, Day NE, Fabry J, Cooper JA. Discovering carcinogens in the occupational environment: A novel epidemiologic approach. J Natl Cancer Inst. 1981;66:217-25.

17. Coughlin S, Chiazze L. Job-Exposure matrices in epidemiologic research and medical surveillance. Occup Med. 1990;5(3):63346.

18. Stevens RG, Davis S. The melatonin hypothesis: electric power and breast cancer. Environ Health Perspect. 1996;36: 573-96.

19. Hansen AM, Garde AH, Hansen J. Diurnal urinary 6-sulfatoxiymelatonin levels among healthy Danish nurses during work and leisure time. Chronobiology Int. 2006;23(6): 1203-15. http://dx.doi.org/10.1080/07420520601100955.

20. Arendt J, Skene DJ. Melatonin as a chronobiotic. Sleep Med Rev. 2005,9:25-39. http://dx.doi.org/10.1016/j.smrv.2004.05.002.

21. Young IM, Leone RM, Francis P, Stovell P, Silman RE. Melatonin is metabolized to JV-acetyl serotonin and 6-hydroxymelatonin in man. J Clinical Endocrinology Metabolism. 1985;60:114-9. http://dx.doi.org/10.1210/jcem-60-1-114.

22. Stevens RG, Rea MS. Light in the built environment: potential role of circadian disruption in endocrine disruption and breast cancer. Cancer Causes Control. 2001;12:279-87. http://dx.doi. org/10.1023/A:1011237000609.

23. Schernhammer ES, Rosner B, Willet WC, Laden F, Colditz GA, Hankinson SE. Epidemiology of urinary melatonin in women and its relation to other hormones and night work. Cancer Epidemiol Biomarkers Prev. 2004:13(6):936-43.

24. Borugian MJ, Gallagher RP, Friesen MC, Switzer TF, Aronson JK. Twenty-four-hour light exposure and melatonin levels among shift workers. J Occup Environ Med. 2005;47(12):126875. http://dx.doi.org/10.1097/01.jom.0000184855.87223.77.

25. Grundy A, Sanchez M, Richardson H, Tranmer J, Boruqian $\mathrm{M}$, Graham $\mathrm{CH}$, et al. Light intensity exposure, sleep duration, physical activity, and biomarkers of melatonin among rotating shift nurses. Chronobiology Int. 2009;26(7):1445-61. http:// dx.doi.org/10.3109/07420520903399987. 
26. Levallois P, Dumont M, Touitou Y, Gingras S, Mâsse B, Gauvin $\mathrm{D}$, et al. Effects of electric and magnetic fields from high-power lines on female urinary excretion of 6-sulfatoxymelatonin. Am J Epidemiol. 2001;154(7):601-9. http://dx.doi.org/10.1093/ aje/154.7.601.

27. Cocco P, Cocco ME, Paghi L, Avataneo G, Salis A, Meloni $\mathrm{M}$, et al. Urinary 6-sulfatoxymelatonin excretion in humans during domestic exposure to 50 herts electromagnetic fields. Neuroendocrinology Let. 2005;26(2):136-42.

28. Nagata C, Nagao Y, Yamamoto S, Shibuya C, Kashiki Y, Shimizu $\mathrm{H}$. Light exposure at night, urinary 6-sulfatoxymelatonin, and serum estrogens and androgens in postmenopausal Japanese women. Cancer Epidemiol Biomarkers Prev. 2008;17(6):141823. http://dx.doi.org/10.1158/1055-9965.EPI-07-0656.

29. Grundy A, Tranmer J, Richardson H, Graham CH, Aronson $\mathrm{JK}$. The influence of light at night exposure on melatonin levels among Canadian rotating shift nurses. Cancer Epidemiol Biomarkers Prev. 2011;20(11):2404-12. http://dx.doi. org/10.1158/1055-9965.EPI-11-0427.

30. Hsing AW, Meyer TE, Niwa S, Quraishi SM, Chu LW. Measuring serum melatonin in epidemiologic studies. Cancer Epidemiol Biomarkers Prev. 2010;19(4):932-7. http://dx.doi. org/10.1158/1055-9965.EPI-10-0004.

31. Zheng W, Chow WH, Yang G, Jin F, Rothman N, Blair A, et al. The Shanghai Women's Health Study: rationale, study design, and baseline characteristics. Am J Epidemiol. 2005;162(11): 1123-31. http://dx.doi.org/10.1093/aje/kwi322.

32. Pronk A, Ji BT, Shu XO, Xue S, Yang G, Li HL, et al. Night-shift work and breast cancer risk in a cohort of Chinese women. Am J Epidemiol. 2010;171(9):953-9. http://dx.doi.org/10.1093/aje/ kwq029.

33. Kromhout H, Vermeulen R. Application of job-exposure matrices in studies of the general population: some clues to their performance. Eur Respir Rev. 2001;11:80-90.
34. Wirth M, Burch J, Violanti J, Burchfiel C, Fekedulegn D, Andrew M, et al. Shiftwork duration and the awakening cortisol response among police officers. Chronobiol Int. 2011; 28(5):446-57. http://dx.doi.org/10.3109/07420528.2011.5731 12.

35. Griefahn B, Robens S. The normalization of the cortisol awakening response and of the cortisol shift profile across consecutive night shifts - an experimental study. Psychoneuroendocrinology. 2010;35:1501-9. http://dx.doi. $\operatorname{org} / 10.1016 /$ j.psyneuen.2010.05.002.

36. Kudielka BM, Buchtal J, Uhde A, Wüst S. Circadian cortisol profiles and psychological self-reports in shift workers with and without recent change in the shift rotation system. Biological Psychology. 2007;74(1):92-103. http://dx.doi.org/10.1016/j. biopsycho.2006.08.008.

37. Cook MR, Graham C, Kavet R, Stevens RG, Davis S, Kheifets L. Morning urinary assessment of nocturnal melatonin secretion in older women. J Pineal Res. 2000;28:41-7. http://dx.doi. org/10.1034/j.1600-079x.2000.280106.x.

38. Hartman TJ, Mahabir S, Baer DJ, Stevens RG, Albert PS, Dorgan JF, et al. Moderate alcohol consumption and 24-hour urinary levels of melatonin in postmenopausal women. J Clin Endocrinol Metab. 2012;97:E65-E68. http://dx.doi. org/10.1210/jc.2011-1904.

39. Masue T, Wada K, Hayashi M, Takeda N, Yasuda K, Deguchi $\mathrm{T}$, et al. Associations of urinary 6-sulfatoxymelatonin with biomarkers related to cardiovascular disease in Japanese women. Metabolism. 2012;61:70-5. http://dx.doi. org/10.1016/j.metabol.2011.05.021.

Received for publication: 1 February 2012 